Thorax (1965), 20, 289.

\title{
Gross fixation methods used in the study of pulmonary emphysema
}

\author{
R. E. S I L V ER T O N \\ From the Pneumoconiosis Research Unit, Llandough Hospital, Penarth, Glam.
}

Fixation of the lung in an expanded position, which will permit a detailed study of the gross anatomy together with the microscopical structures, is a problem which has confronted research workers for more than a century. Several techniques have been developed, most of which have as their primary objective fixation of the lung at some specific degree of inflation, but no one method has been universally adopted. This paper is a critical review of the common methods.

Any method selected as a routine technique for the preservation of lung specimens should meet the following requirements.

(1) It should restore and maintain the normal shape of the specimen without introducing artefacts due to overdistension or surface flattening. Furthermore, the degree of inflation should bear a definite relationship to the lung compliance of the specimen.

(2) It should permit the preparation of microscopical slides of an acceptable histological standard and also allow for the preparation of papermounted whole lung sections. This method, which at the present time is the most valuable technique for the macroscopical study of pulmonary emphysema, facilitates the exchange of macroscopical specimens between research establishments.

(3) It should be simple to apply and require the minimum of space, equipment, and supervision.

Laennec (1832), in his classical work $A$ Treatise on the Diseases of the Chest and on Mediate Auscultation, wrote of emphysema, 'To enable us to have a correct notion of this disease, we must inflate the affected lungs and immediately dry them. If they are then cut into slices with a fine instrument, we perceive at once that the air cells are almost always more dilated than they appear externally; insomuch that those which form a projection on the surface, of the size of a hemp-seed, are found capable of containing a cherry-stone. We observe, moreover, that some of the cells are simply dilated, while others are ruptured, the intervening portions of several being destroyed more or less completely'. The method that Laennec used to air-dry his specimens has been attributed to Picard (1832). Formaldehyde was only introduced as a fixative at the end of the nineteenth century (Blum, 1893).

Tobin (1952) described a method for preparing air-dried lungs by inflation with compressed air at a pressure of 5 to $50 \mathrm{~mm}$. of mercury, the pressure used being dependent on the elasticity of the specimen. Air-drying alone is not a means of fixation, and specimens so prepared are not permanently preserved. Histologically, the end product is quite unacceptable, and the method can be disregarded for routine purposes. Oderr, Pizzolato, and Ziskind (1959) used air-dried specimens in their early radiological studies, but later modified their technique by using air-dried specimens previously fixed by distension with alcohol ; this method is unsuitable for general work.

Since the function of the lung is to effect gaseous exchange, vapour fixation appears to be the ideal choice if a suitable technique can be perfected. This applies in particular when post-fixation radiological studies are to be undertaken. Radiography of the lungs after fixation with liquid formalin is unsatisfactory, because by filling the air spaces with fluid instead of air the contrast necessary to study the shadows of the tissue is lost.

\section{VAPOUR FIXATION}

Fixation by passing formaldehyde vapour into the airways has been used by a number of workers. The methods devised can be divided into the following groups according to the temperature of the formaldehyde solution used to produce the vapour: (1) cold formaldehyde vapour (temperature at source $20^{\circ}$ C.) ; (2) warm formaldehyde vapour (temperature at source $60^{\circ} \mathrm{C}$.) ; and (3) hot formaldehyde vapour (temperature at source $\left.100^{\circ} \mathrm{C}.\right)$. 
COLD FORMALDEHYDE VAPOUR Several workers have used cold formaldehyde vapour in the inflated lung. Blumenthal and Boren (1959) employed it with compressed air when making a three-dimensional study of emphysematous lungs. Fixation was effected by inflating the specimen with formaldehyde vapour produced by bubbling compressed air through a solution of concentrated formaldehyde at room temperature (Fig. 1). Fixation by this method took three to five days, after which the specimen was dehydrated by air-drying. The degree of inflation was assessed by visual observation and the air-drying was achieved by passing compressed air through the specimen.

Blumenthal and Boren state that, owing to a continual leakage of air from the lung surface, no static pressure could be measured, but they observed that the usual flow required to maintain the lung in an inspiratory state was $51 . / \mathrm{min}$. with a maximal flow of $10 \mathrm{l} / \mathrm{min}$. The mean pressure applied was 1.35 to $18.2 \mathrm{~cm}$. of water, while the maximal pressure at the start of inflation was $36 \mathrm{~cm}$. of water. A similar method of fixation was used by Hentel and Longfield (1960).
The prime objective of these workers was the $\overrightarrow{\vec{s}}$ stereoscopic study of the lung structure, and foro this purpose fume fixation followed by air-dryingo can be regarded as an invaluable auxiliary tech $\frac{\bar{s}}{5}$ nique, particularly when photography is required $\stackrel{\Phi}{\Phi}$ It is not suitable, however, for general purposes? The histological results obtained do not permitdetailed microscopical study. Slicing of the lung is a relatively easy matter immediately after fixa- $\vec{\omega}$ tion and drying, but gross specimens stored foro longer than two weeks become extremely brittle while thin slices prepared from them are easilyin damaged and show a tendency to curl. Cote Korthy, and Kory (1963), who used specimensi fixed with formalin fumes and dehydrated witho alcohol vapour and air, overcame this last faul by sealing the lung slices, which they cut on ameat slicing machine, in a plastic laminate.

Jones (1960) used the vapour produced fromk two separate containers of $50 \%$ formalin ande $50 \%$ ethyl alcohol. Fixation was continued fors several days. She concluded, however, that the unreliability and slowness of the technique made it impracticable for routine use.

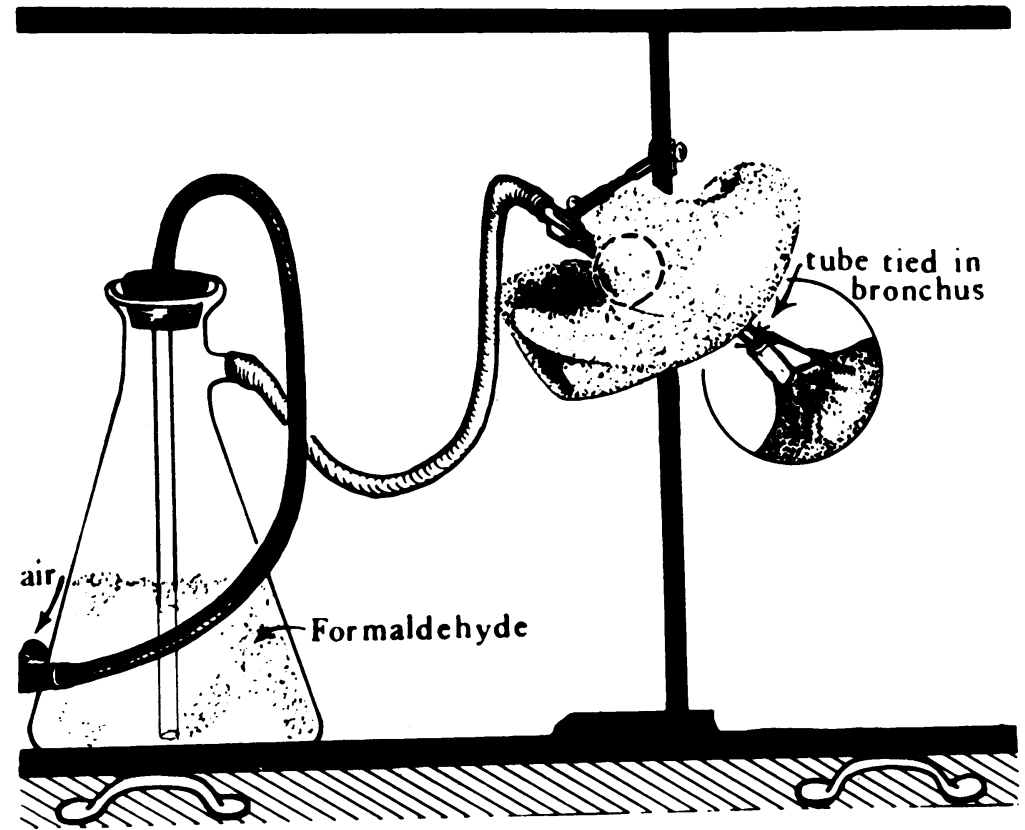

FIG. 1. Illustrates the technique of inflation used by Blumenthal and Boren (1959). A vapour of formaldehyde fumes obtained by bubbling air through formalin $\left(20^{\circ}\right.$ C.) passes into and inflates the lung suspended by the bronchial attachment. The excess fumes are removed by a hood. The insert shows a method of attachment to the bronchus.

[Reproduced by courtesy of the authors and the editor of American Review of Tuberculosis (now American Review of Respiratory Diseases).] 
Cureton and Trapnell (1961) inflated a series of lungs with formaldehyde gas obtained by using the vapour above the fluid in a half empty carboy of concentrated $40 \%$ formaldehyde solution. The carboy was selected as the source for the gas in view of the large surface area and the proportionally larger volume of gas produced. After inflation and ligation of the bronchus the specimen was radiographed and then floated on a diluted $(20 \%)$ solution of formalin, the surface being covered with a cloth soaked in the same solution. Specimens were left for 48 hours before further examination.

Of 42 cases which were preserved by this method, the authors reported seven as being incompletely fixed. The failure in two cases was attributed to the thick mucus in the bronchi, and in another four it was apparently due to a drop in the concentration of the gas in the carboy. The remaining case contained a solid haemorrhagic infarct which, not surprisingly, was found on examination to be incompletely fixed.

The presence of mucus in the bronchi prevents complete penetration of the formaldehyde vapour by this method, which is therefore unsuitable for studying chronic non-specific lung disease, though the histological results obtained with those specimens which are successfully preserved can be satisfactory.

WARM FORMALDEHYDE VAPOUR Pratt and Klugh (1961) stated that an airtight lung will not fix if a steady pressure of formaldehyde fumes is applied to it through the bronchus. They developed a method in which, after post-mortem lung function studies, the lung was fixed by continuously changing the gas contained within it. The specimen was cannulated with a wide bore connector and suspended in an artificial thorax constructed out of Plexiglas (perspex). By means of a cylinder and piston the suspended lung was made to 'breathe' the fumes produced by heating a solution of concentrated formaldehyde to a temperature of $60^{\circ} \mathrm{C}$. Breathing was produced by suction on the surface of the lung. A one-way valve in the tubing between the warm formaldehyde and the lung ensured that new fumes were constantly being aspirated into the specimen. Fixation took 12 to 18 hours. As the specimen still retained a considerable degree of elasticity after fixation it was dried by a continuous air stream.

During fixation and drying the maximal pressure applied was that which had previously been determined as correct for each lung from static inflation and deflation tests performed on the un- fixed specimen and recorded on a spirometer. Drying was continued for five to eight days, during which the air diffused through the pleura and dehydrated the specimen. After five days the lung was weighed daily until a constant weight was recorded. The specimen was then considered to be dry and free from risk of further shrinkage.

The lungs were then cut into slices $1 \mathrm{~mm}$. in thickness on a band saw fitted with a double-bevel, straight-edged knife and examined under a stereoscopic microscope. The authors emphasize the need to cut thick sections in emphysematous lungs.

This method was developed to relate postmortem functional studies with gross pathological changes in lungs fixed in a distended state. The findings have been reported by Pratt, Haque, and Klugh (1962), and by Pratt, Jutabha, and Klugh (1963).

Photographs taken through the stereoscopic microscope reveal striking pictures of lung structure and clearly illustrate various forms of pulmonary emphysema. This method is the best technique for preparing air-dried specimens, but there are obviously considerable limitations. No information on the histological appearances using the method was given ; it seems probable that shrinkage and distortion, inherent faults associated with air-dried specimens, would be present.

No physiological or pathological variations were observed in examinations performed immediately on fresh specimens, or at a later date on lungs subjected to quick freezing and subsequent storage and thawing. The number of specimens that can be examined by this method is obviously limited.

HOT FORMALDEHYDE VAPOUR The use of hot formaldehyde vapour as a fixative for the preservation of lung specimens was first described by Weibel and Vidone (1961). The method was developed in order to study quantitatively the number and size of lung structures. The results have been reported by Weibel and Gomez (1962), by Dunnill (1962a), and by Weibel (1963).

Fixation with hot formaldehyde vapour is effected by cannulating the bronchus of the specimen and suspending it in a perspex box. Suction is applied to expand the lung to a position slightly less than that of maximum inspiration. The authors determined the degree of inflation by estimating visually the course of the pressurevolume curves (Radford, 1957; Mead, 1961) and assessing when the point of inflection had just been passed. A solution of strong formalin (con- 

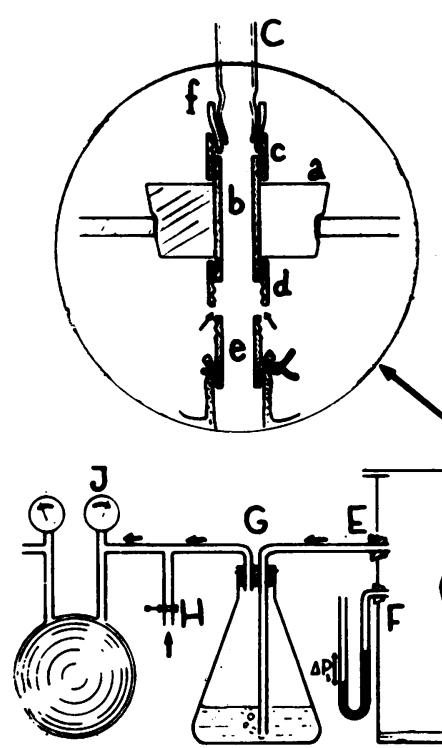

FIG. 2. The apparatus used by Weibel and Vidone (1961 in their hot formaldehyde vapour method (temperature at source $100^{\circ} \mathrm{C}$.). $A$, concentrated formaldehyde; $B$, ' $T$ ' $\underline{\overline{\bar{D}}}$ junction to act as safety valve; $C$, ' $T$ ' junction to act as $\frac{\bar{S}}{\partial}$ by-pass for air ; $D$, inlet for air ; $E$, aperture to vacuum $\triangle$ pump ; $F$, manometer; $G$, water trap; $H$, by-pass to control suction exerted on specimen; $J$, vacuum pump ; $K$, water supply to escape valve; $L$, syphon from escape $\vec{\circ}$

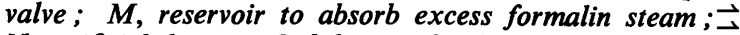
$N$, artificial thorax; $O$, lid to artificial thorax $;, \operatorname{clamp} \vec{\omega}$ to control flow of formalin steam. Inset: the threaded metal pipe connector recommended by Moolten (1935) for $\times$ cannulating the lung.

[Reproduced by courtesy of the authors and the editor of $A$ the American Review of Respiratory Diseases.]

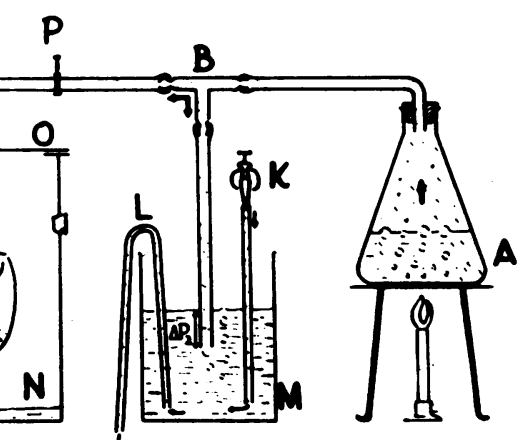

and the tissue immediately adjacent to it. Dunnillo (1962b) stated that he also obtained his best results by using concentrated formaldehyde as theo steam source.

Details for determining the shrinkage producedoby the action of the hot formaldehyde vapour are given by Weibel and Vidone (1961) and by Weibel (1963).

Secondary fixation with Zenker's solution pre-o vents detailed macroscopical studies and the pre- $>$ paration of whole lung sections. Silverton (1964) has illustrated, however, that secondary fixation is not essential and that macroscopical studies can be undertaken and whole lung sections prepared N when concentrated formaldehyde is used as the source of the steam.

Greenberg, O’Neal, and Jenkins (1964) have⿳亠丷厂 also used hat formaldehyde vapour as a fixative in the study of chronic pulmonary disease. They? used concentrated formaldehyde as the source of vapour but buffered the solution before heating (no information on $p \mathrm{H}$ is given). Acid formalin pigment in specimens fixed with hot formaldehydo vapour has been noted by Silverton (1964), anof the buffered solution may eliminate this troublesome pigment. 
BRONCHIAL INSUFFLATION WITH LIQUID FORMALIN

The majority of workers who fix the lung by inflation do so by the instillation of liquid formalin via the main bronchus. The methods which have been suggested for this purpose can be divided for convenience into two groups, according to the time for which the pressure is maintained: (1) constant pressure inflation, and (2) constant pressure inflation and fixation.

CONSTANT PRESSURE INFLATION In this group of methods a constant pressure is used to inflate the lung (disregarding the variation in pressure produced as the level of the fixative in the reservoir falls) but is not maintained during subsequent fixation.

Hartroft and Macklin (1943) emphasized the importance of controlling the degree of expansion produced by fixation in their studies of alveolar size. The lungs and heart were carefully removed en masse, avoiding damage to the pleura. Measurements were then taken from the caudal border of the neck of the first rib as the top to the lower border of the eleventh rib as the bottom. The measurement was taken on both sides, lateral to the vertebral column, using obstetrical callipers. This measurement was then used for adjusting the degree of inflation to that corresponding with the superior-inferior dimensions.

The lung was cannulated and floated in a bath of formalin, the purpose of this being to provide support during inflation. A funnel was connected to the cannula, and a small quantity of picroformol (Bouin, 1897) was poured and allowed to run into the bronchial tree. The specimen was then agitated to permit air bubbles to escape. The procedure was repeated until most of the residual air had been replaced by fixative. When air bubbles no longer emerged the cannula was connected to a reservoir of the fixative, placed at a height of $30 \mathrm{~cm}$. above the specimen, and the inflation was resumed. The degree of expansion was checked by calliper readings during this process, and the lung was inflated until the length exceeded by $15 \%$ the pleural cavity measurement.

Hartroft and Macklin state that it is necessary to overfill human lungs to this extent to provide for the inevitable shrinkage that follows a loss of fluid through the visceral pleura.

When the expansion was complete the tubing was clamped off and the specimen was left in the supporting bath of fixative for a minimum period of three weeks. During this time further measurements were recorded. The lung was eventually cut into parallel slices, $3 \mathrm{~cm}$. in thickness, while immersed in formalin.

The method was developed to compare the size of the alveoli of human lungs with those of animals, the lungs of which were fixed by vascular perfusion while still in the intact thorax. The alveoli were measured in sections cut at $25 \mu$ and although suitable for experimental work of this nature, neither the method nor the fixative used would be practicable for routine use and macroscopical studies.

Gough and Wentworth (1949, 1960) recommended that, when whole lung sections are to be prepared, the lungs should be fixed in an expanded state by running formol-acetate into the main bronchus from a reservoir at a height of approximately $120 \mathrm{~cm}$. above that of the specimen. The lung is cannulated and fully distended with fixative. The cannula is then disconnected, and the inflated specimen is placed in a vessel containing sufficient formol-acetate to allow it to float freely without distortion from pressure. It is then covered with a cloth soaked in the same solution to prevent surface drying. The bronchus is neither tied nor plugged. The minimum period of fixation required with this method is 48 hours. Up to 2 litres of fixative may be run into the lung, and a further 3 litres are required to float the distended specimen. At the present time Gough and Wentworth (personal communication) use a small pump to inflate the lung with formol-acetate. In all other respects the technique remains the same.

In the United States of America it is recommended that the lungs be expanded by bronchial insufflation with formol-acetate, using a pressure not exceeding 25 to $30 \mathrm{~cm}$. of water (Report of Committee on Preparation of Human Lungs for Macroscopic and Microscopic Study, 1959). The pulmonary vessels should be ligated before fixation to prevent exsanguination and vascular collapse. The fixative is run into the specimen until the lung boundaries show normal contours, after which the bronchus or trachea is tied off with cord, and the specimen is immersed in a large volume of the fixative. This method was used by Anderson and Foraker (1962) in their study of the relative dimensions of bronchioles and parenchymal spaces in lungs from normal and emphysematous patients. Wyatt, Fischer, and Sweet (1964) also used this method in their studies on pulmonary emphysema.

Sills (1962) has described a method for the study of lung structure and function; in this, the lung is expanded and fixed with an alcohol-formaldehyde-glycol mixture introduced into the bronchial 
tree by gravity. No details of the pressure used are given. Fixation is continued for 12 to 72 hours, after which areas of tissue for histological examination are selected and excised with a stainless steel circular knife patterned after a cork borer and the holes are plugged with corks. The lung is then suspended in a bell jar, and suction is applied until the pressure is lowered to $-2 \mathrm{~cm}$. $\mathrm{Hg}$, when the fixative flows out of the lung. The bell jar is then drained and suction is reapplied until a vacuum of $-6 \mathrm{~cm}$. $\mathrm{Hg}$ is recorded. This pressure is maintained for two to three days until the specimen is dried and does not collapse.

The whole method is ingenious in that it incorporates radiological studies of the vascular and bronchial tree as well as histological slides prepared from liquid-fixed tissue before dehydration of the specimen. As a specialized research technique it has a great deal to offer, but the method is too complex and time-consuming for the preparation of a large number of specimens.

CONSTANT PRESSURE INFLATION AND FIXATION The earliest attempt to produce uniform fixation of the lung using a controlled pressure during the period $\stackrel{\overrightarrow{\vec{\rho}}}{\stackrel{\vec{\rho}}{\circ}}$ of inflation and fixation was that by Moolten: (1935). He suspended the specimen in a bell jar. Suction applied to the jar inflated the lung, which $\overrightarrow{\widetilde{\sigma}}$ was then exposed to carbon monoxide to 'fix the haemoglobin of the lung a permanent red. Fixation was effected by slowly introducing 2 to $\overrightarrow{0}$ 3 litres of fixative (Kaiserling, 1897) via the cannulated bronchus. The specimen was maintained $\vec{\omega}$ in the expanded state for 12 to 18 hours.

Moolten considered this method to be ideal $\vec{x}$ for the study of such conditions as bronchiectasis, $\mathbb{O}$ bullous emphysema, suppurative pneumonia, and + tuberculosis, and he claimed a much better histo- $-\infty$ logical picture of the lung even in normal lungs.

The suction applied to inflate the lung varied ${ }^{?}$ from 10 to $20 \mathrm{~cm}$. of water. This pressure on the $\vec{c}$ fixative being introduced into the specimen had to be repeatedly regulated. The method never becamevery widely used for routine purposes owing tos the apparatus required and the constant attention. necessary.

Heard (1958) described a method for fixing lungs in a state of full expansion by means of

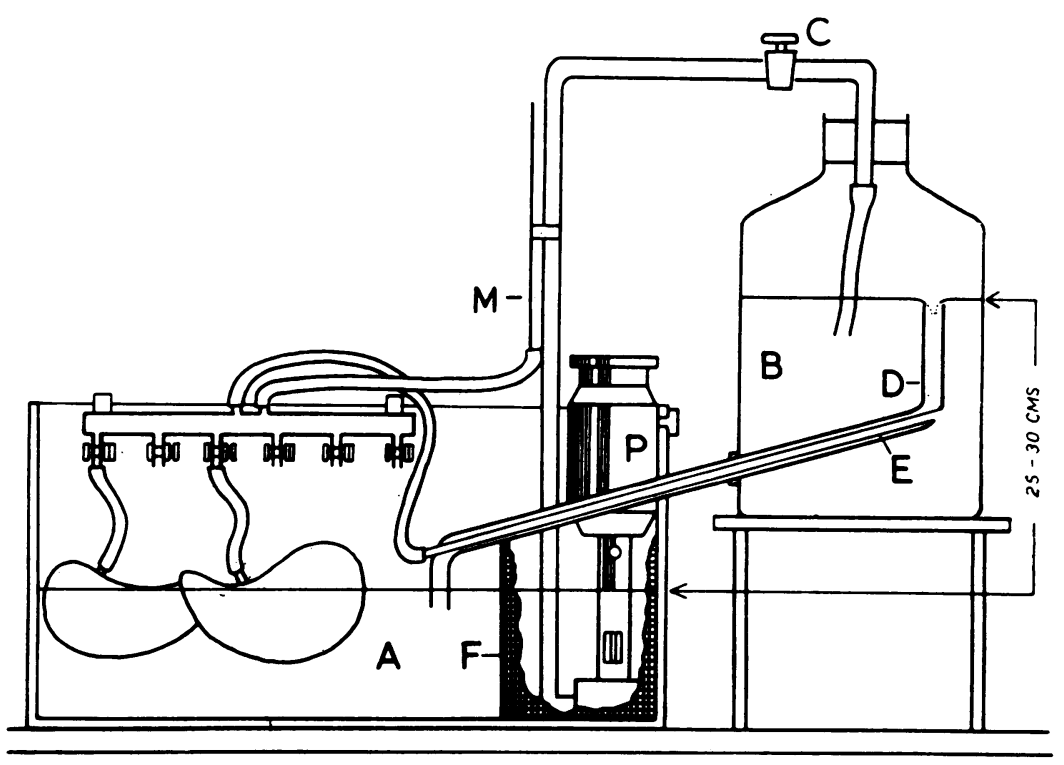

FIG. 3. The apparatus used by Heard (1960) in his constant pressure and inflation technique. The pump $(P)$ raises formalin to the upper container $(B)$ where it overflows down the pipe $(D)$. The manifold is supplied by the tube $(E)$, and six lungs (or more) can be fixed at one time. Fixation takes 72 hours. $A$, lower container ; $B$, upper reservoir ; $C$, control tap; $D$, overflow pipe ; E, feed pipe to manifold; $F$, filter for pump : $M$, manometer ; $P$, pump.

[Reproduced by courtesy of the author and the editor of the American Review of Respiratory Diseases.] 
constant pressure, and has further developed it (Heard, 1960) to incorporate a centrifugal pump to maintain a constant pressure of 25 to $30 \mathrm{~cm}$. of water by recirculation of the fixative. As much mucus as possible is sucked out of the bronchial tree using a rubber catheter; the main bronchus is then cannulated and connected to the apparatus as illustrated (Fig. 3). Fixation is achieved by bronchial insufflation with $25 \%$ formalin (concentrated formaldehyde solution $40 \%, 1$ part; water, 3 parts), and the pressure is maintained for 72 hours. Although a pressure of $10 \mathrm{~cm} . \mathrm{H}_{2} \mathrm{O}$ is quite sufficient to expand the surface alveoli of normal lungs, the higher pressure of 25 to 30 $\mathrm{cm} . \mathrm{H}_{2} \mathrm{O}$ was adopted to overcome bronchial obstruction produced by mucus and to prevent surface flattening.

Using water displacement, Heard showed that the volume measurements, made at intervals during fixation and for some months afterwards, remained remarkably constant. By increasing the pressure to $120 \mathrm{~cm} . \mathrm{H}_{2} \mathrm{O}$ an increase of $7 \%$ in the lung volume was recorded, and a pressure of $150 \mathrm{~cm}$. $\mathrm{H}_{2} \mathrm{O}$ or above was found to be capable of producing a rupture of the lung. This method overcomes some of the disadvantages of using pressure for the period of inflation only, such as leakage through surface tears and the decrease in lung volume produced by surface flattening. In common with all specimens fixed by expansion with liquid formalin, and in emphysematous lungs especially, collapse occurs when the specimens are sliced for examination. Heard's technique has been criticized by Hartung (1962) on the grounds that, due to variations in lung compliance between normal and diseased lungs, those with emphysema are overdistended.

In reply to this criticism Heard (1962) stated that he had endeavoured to fix the lung at a volume which was as near as possible to that measured in the patient's own thorax in full inspiration. Comparison with lung volumes calculated from retrospective radiographs in life showed supporting evidence for this.

Hartung $(1960,1962)$ described a formalin technique in which excised lungs are expanded by a controlled change in the volume. The bronchus is cannulated and the specimen is placed in a sealed container filled with formalin. The bronchial outlet is connected to a reservoir of the same fixative. Suction applied to the container in which the specimen is immersed produces a variation of volume to which the lung responds, causing it to 'inhale' formalin from the reservoir. The residual air having been calculated from the weight and volume of the specimen, the lungs can be expanded to a given point within the respiratory cycle according to the formula for normal lung volumes or, when available, by referring to individual clinical data. Although this method appears to offer certain advantages, it still does not overcome the complication of collapse on slicing the lung. The method is time-consuming and is not intended for routine use.

Trapp and Allan (1963) used a constant pressure of $90 \mathrm{~cm}$. of formalin to inflate and fix the surgical specimens used in their investigation, and stated that at this pressure the pleura kept a close approximation of the normal intrathoracic shape and size of the lung.

\section{DISCUSSION}

It is clear that no single method has yet been devised which meets the individual requirements of the majority of research workers engaged in the study of pulmonary emphysema. The problem is bound up in part with the post-fixation studies to be undertaken, the number of specimens handled, and the facilities available.

When radiological, stereoscopic, and quantitative studies of the fixed specimen are to be made, vapour fixation obviously has many points in its favour, but valuable histological material may be lost in the process of air drying. Weibel (1963) considers it essential to employ a more natural fixation technique than that of bronchial insufflation with liquid formalin, but points out that the extraction of all moisture from the lung results in distortion and shrinkage.

The hot formaldehyde vapour method of Weibel and Vidone, modified as suggested either by Silverton (1964) or Greenberg et al. (1964), in conjunction with the whole lung section technique of Gough and Wentworth (1960), could provide a compromise for quantitative, macroscopical, radiological, and histological studies. The rapid fixation by this method is due partly to the temperature of the vapour, partly to the supersaturation of the vapour, and partly to its better penetrating powers. Thus, unlike the cold vapour method used by Cureton and Trapnell (1961), no unfixed specimen should be encountered when using this method. During the process of fixing lungs with the hot formaldehyde vapour method Greenberg et al. (1964) recorded a hilar temperature of $78^{\circ} \mathrm{C}$., whereas that of the artificial thorax averaged $40^{\circ} \mathrm{C}$.

Bronchial insufflation with liquid formalin will undoubtedly continue to be the major method of 
preserving lungs for many years to come. The major differences of opinion which exist concerning fixation by bronchial insufflation with liquid formalin centre on the following points: $(a)$ the inflation pressure to be used; $(b)$ whether or not to ligate the vessels and bronchi; and $(c)$ the need to maintain the pressure during fixation.

The constant pressure technique of Heard $(1958,1960)$ has a great deal to offer from the point of view of retaining the shape of the specimen, particularly when surface tears are involved. On the other hand, the criticism of the method made by Hartung (1962) is quite valid. The method described by Hartung $(1960,1962)$ is based on sound principles and is probably the best method described to date, but it is very time-consuming, and could not be applied in a routine laboratory.

Ligating the vessels before fixation appears to be reasonable, particularly if microscopical measurements of the alveoli are to be made, but such measurements are still suspect due to distortion when selecting the block, shrinkage during processing, compression of the section on cutting, and variations in water temperature when floating the section out. For accuracy it is essential to take careful measurements of the selected blocks before processing and after sectioning to assess the degree of distortion and shrinkage produced by the processing and sectioning.

The question of the ideal inflation pressure to use is complicated as it will obviously vary between specimens, depending on the degree of normality. A modified version of the constant pressure apparatus described by Heard (1960) is currently being investigated in this Unit with a view to developing a simple technique which might surmount this particular problem and be applicable for use in the routine laboratory.

It is perhaps worth noting that ligation of the vessels reduces the blocking of the filter surrounding the centrifugal pump; this often appears to become clogged with the blood exuded from the specimen during fixation.

The method of simply distending lungs with formol-acetate is undoubtedly the most convenient and finds the widest support when inflation of the lung is practised. Although this method leaves much to be desired, it would be an important step in the correlation of the pathology of chronic nonspecific lung disease if all lung specimens on which a detailed study of pulmonary anatomy is to be made were inflated by using this technique, coupled with ligation of the vessels and bronchus, and using a pressure not exceeding $30 \mathrm{~cm}$. of water. After inflation the specimen should be sus- pended in a large bath of the fixative and covered with a paper towel to prevent surface drying.

A great deal of progress has been made in recent years on the morphology of chronic nonspecific lung disease. If the results of research workers throughout the world are to be correlated. however, it is of the utmost importance that a real attempt should be made to introduce some uniformity in the technique used to inflate the lung.

Quantitative studies are now being undertaken in this Unit on specimens fixed by some of the methods described, and it is hoped that the results will be published in the near future.

\section{SUMMARY}

A criterion is given for the preservation of lung specimens on which both gross anatomical and microscopical studies are to be made. A number of fixation techniques are described. Those employing formaldehyde vapour as the fixative are subdivided into groups according to the temperature of the formaldehyde solution used to produce the vapour. Methods employing liquid formalin as the fixing agent are grouped according to the time for which the pressure used to inflate the lung is maintained.

The relative advantages and disadvantages of each method are described and discussed.

I wish to express my appreciation and gratitude to Dr. J. C. Gilson, Director of the Unit, and to Dr. J. C. Wagner. Scientific Officer in charge of the Pathology Section. for their advice and criticism so freely given during the preparation of this paper.

\section{REFERENCES}

Anderson, A. E., Jr., and Foraker, A. G. (1962). Relative dimensions of bronchioles and parenchymal spaces in lungs from normal subjects and emphysematous patients. Amer. J. Med., 32, 218. Blum, F. (1893). Der Formaldehyde als Härtungsmittel. Vorläufige Mittheilung. Z. wiss. Mikr., 10, 314

Blumenthal, B. J., and Boren, H. G. (1959). Lung structure in three dimensions after inflation and fume fixation. Amer. Rev. Tuberc., 79, 764 .

Bouin, P. (1897). In Pathological Technique. By F. B. Mallory, p. 45. Saunders, London and Philadelphia.

Cote, R. A., Korthy, Agnes L., and Kory, R. C. (1963). Laminated lung macrosections; a new dimension in the study and teaching of pulmonary pathology. Dis. Chest, 43,1 .

Cureton, R. J. R., and Trapnell, D. H. (1961). Post-mortem radiography and gaseous fixation of the lung. Thorax, 16, 138.

Dunnill, M. S. (1962a). Quantitative methods in the study of pulmonary pathology. Ibid., 17, 320 .

(1962b). Personal communication.

Gough, J., and Wentworth, J. E. (1949). The use of thin sections of entire organs in morbid anatomical studies. J. roy. micr. Soc., $69,231$.

(1960). Thin sections of entire organs mounted on paper. In Recent Advances in Pathology,

Greenberg, S. D. O'Neal, R. M., and Jenkins, D. E. (1964). A rapid method of inflation-fixation for morphologic study of chronic method of inflation-fixation for morphologic

Hartroft, W. S., and Macklin, C. C. (1943). Intrabronchial fixation of the human lung for purposes of alveolar measurement, using $25 \mu$ microsections made therefrom. Trans. roy. Soc. Can., Sect. $V$ (Biol. Sci.), 3rd ser., 37, 75. 
Hartung, W. (1960). Gefrier-Grosschnitte von ganzen Organen, speziell der Lunge. Zbl.allg. Path. path. Anat., 100, 408. (1962). Pressure-fixation in study of pulmonary emphysema. Amer. Rev, resp. Dis., 85, 287.

Heard, B. E. (1958). A pathological study of emphysema of the lungs with chronic bronchitis. Thorax, 13, 136.

(1960). Pathology of pulmonary emphysema. Methods of study. Amer. Rev. resp. Dis., 82, 792.

- (1962). Pressure fixation in study of pulmonary emphysema. lbid., \& 5, 599.

Hentel, W., and Longfield, A. N. (1960). Stereoscopic study of the inflated lung. Dis. Chest, $38,357$.

Jones, E. (1960). Study of lung specimens prepared by fume fixation. Amer. Rev. resp. Dis., 82, 704.

Kaiserling, C. (1897). Weitere Mittheilungen über die Herstellung möglichst naturgetreuer Sammlungspräparate. Virchows Arch. path. Anat., 147, 389.

Laennec, R. T. G. (1832). A Treatise on the Diseases of the Chest and on Mediate Auscultation. Translation by J. Forbes from 3rd French edition, p. 148. Samuel and Wm. Wood, New York, 1838.

Mead, J. (1961). Mechanical properties of lungs. Physiol. Rev., 41, 281 .

Moolten, S. E. (1935). A simple apparatus for fixation of lungs in the inflated state. Arch Path., $20,77$.

Oderr, C. P., Pizzolato, P., and Ziskind, J. (1959). Microradiographic techniques for study of emphysema. Amer. Rev. resp. Dis., 80, No. 1, Part 2, p. 104

Picard (1832). Footnote on page 154 in A Treatise on the Diseases of the Chest and on Mediate Auscultation, by Laennec, R. T. G. Translation by Forbes from 3rd French edition (1838). Samuel and Wm. Wood, New York.

Pratt, P. C., Haque, M. A., and Klugh, G. A. (1962). Correlation of postmortem function and structure in panlobular pulmonary emphysema. Lab. Invest., 11, 177.
_ Jutabha, P., and Klugh, G. A. (1963). The relationship between pigment deposits and lesions in normal and centrilobular emphysematous lungs. Amer. Rev. resp. Dis., 87, 245.

- - and Klugh, G. A. (1961). A technique for the study of ventilatory capacity, compliance, and residual volume of excised lungs and for fixation, drying and serial sectioning in the inflated state. Ibid., 83, 690 .

Radford, E. P. J. (1957). Recent studies of mechanical properties of mammalian lung. In Tissue Elasticity by J. W. Remington, ed. Amer. Physiol. Soc. Pp. 177-190.

Report of Committee on Preparation of Human Lungs for Macroscopic and Microscopic Study (1959). Amer. Rev. resp. Dis., 80, No. 1, part 2, p. 114 .

Sills, B. (1962). A multidisciplinary method for study of lung structure and function. Ibid., 86, 238.

Silverton, R. E. (1964). A comparison of formaldehyde fixation methods used in the study of pulmonary emphysema. J. med. Lab. Technol., 21, 187.

Tobin, C. E. (1952), Methods of preparing and studying human lungs expanded and dried with compressed air. Anat. Rec., 114, 453 .

Trapp, W. G., and Allan, M. L. (1963). Changing indications for the resection of pulmonary tuberculosis. Dis. Chest $, 43,486$.

Weibel, E. R. (1963). Morphometry of the Human Lung. Springer, Berlin.

and Gomez, D. M. (1962). Architecture of the human lung. Science, 137, 577.

and Vidone, R. A. (1961). Fixation of the lung by formalin steam in a controlled state of air inflation. Amer. Rev. resp. Dis., 84, 856 .

Wyatt, J. P., Fischer, V. W., and Sweet, H. C. (1964). The pathomorphology of the emphysema complex. Ibid., 89, part 1, p. 533, Part 2, p. 721. 